\title{
Experimentação mediante vídeos: concepções de licenciandos sobre possibilidades e limitações para a aplicação em aulas de química
}

Wilmo Ernesto Francisco Junior

Railane Inácio dos Santos

\begin{abstract}
Resumo
Neste trabalho foram investigadas as concepções de licenciandos de distintas Universidades (Universidade Federal de São Carlos e Universidade Federal de Rondônia) sobre o uso de vídeos para a experimentação, debatendo-se a experimentação mediante vídeos como possibilidade para determinadas situações de ensino. A coleta de dados foi realizada por meio de um questionário contendo questões de caráter discursivo que solicitavam a comparação da experimentação em tempo real com a experimentação por vídeos. A maioria das concepções dos estudantes foi parecida, explicitando algumas visões de cunho empirista e de uma ciência linear. Porém, a experimentação por meio de vídeos se mostrou plausível, considerando como aspectos principais para a realização dessa atividade: (i) a falta de laboratório nas escolas, (ii) o perigo que certos experimentos podem apresentar e (iii) a redução de tempo e de custos dos experimentos.
\end{abstract}

Palavras-chave: experimentação, vídeos, tecnologias da informação e comunicação.

\footnotetext{
Abstract

Experimentation by video: students' conceptions about possibilities and limitations to chemistry classrooms

In this research were investigated students' conceptions from distinct universities (Federal University of Sao Carlos and Federal University of Rondonia) about the use of videos to experimental activities, discussing the use of video as possibility to some teaching situations. Date was obtained by questionnaires in which were solicited comparisons between experimentation by video and traditional experimentation. The most conceptions were similar and revealed some empiricist aspects and a linear science vision. However, the use of videos to practical activities was seen as plausible, mainly in: i) absence of laboratories in
} 
the schools, ii) some dangerous experiments and to iii) decrease costs and the time spent in experiments.

Keywords: experimentation, video, information and communication technologies.

\section{Introdução}

Não é de agora que se atribui à atividade experimental caráter motivador e capacidade de estimular alunos para o aprendizado. Alguns trabalhos (Galiazzi et al., 2001; Galiazzi e Gonçalves, 2004; Gonçalves e Galiazzi, 2004) elencaram quais seriam os objetivos da atividade experimental na percepção de professores e estudantes das áreas científicas. Dentre os objetivos identificados aparecem: motivar e estimular os estudantes; melhorar a aprendizagem; verificar fatos e princípios estudados anteriormente; esclarecer a teoria; comprovar a teoria; desenvolver as habilidades de observação, reflexão, formulação de hipóteses; e adquirir habilidades técnicas de laboratório. Não há como negar que a experimentação esteja vinculada à boa parte de tais objetivos e às relações do processo de ensino e aprendizado. Todavia, a visão empiristaindutivista das atividades experimentais é um dos aspectos problemáticos identificados em conjunto a uma crença de que os experimentos seriam incondicionalmente promotores da aprendizagem e da motivação (Galiazzi e Gonçalves, 2004; Gonçalves e Marques, 2006).

A experimentação também contemplaria outras atribuições, como o desenvolvimento da capacidade crítica e indagadora pela qual os estudantes analisam e interpretam fenômenos, assim como desenvolver outras competências importantes não apenas para o ensino da ciência, como a leitura, a escrita e a argumentação (Oliveira e Carvalho, 2005; Francisco Junior, Ferreira e Hartwig, 2008). A problematização como um princípio no desenvolvimento de atividades experimentais configurar-se-ia, dessa maneira, como alternativa para superar o caráter meramente ilustrativo de conhecimentos teóricos que, às vezes, a elas se atribui (Gonçalves e Marques, 2006; Francisco Junior, Ferreira e Hartwig, 2008).

Para além da experimentação, atualmente muito se tem pesquisado sobre o ensino da ciência, sendo boa parte destas pesquisas preocupada com a busca de novas alternativas e atividades que também estabeleçam as relações entre motivação, interesse e aprendizagem (Laburú, 2006). Recursos didáticos diversos, como os recursos audiovisuais, se apresentam como uma alternativa que pode contribuir para o aumento de interesse dos alunos pela disciplina, possibilitando a construção do conhecimento de forma dinâmica, interativa e não linear, servindo como aliado no trabalho do professor em sala de aula e transformando os estudantes em sujeitos 
ativos da aprendizagem (Corrêa e Ferreira, 2008). A atividade em vídeo pode exercer função informativa, motivadora, expressiva, investigativa, avaliativa e lúdica. Todas essas funções aliadas ao constante exercício da imaginação se colocam como importantes ferramentas no ensino e na aprendizagem (Marcelino Júnior et al. 2004).

A linguagem audiovisual consegue chegar e ir além do que o ser humano percebe através de imagens básicas, centrais, simbólicas e padronizadas que de alguma forma se apresentam e se relacionam, provocando diferentes emoções e sensações (Arroio e Giordan, 2006). O vídeo pode atuar no processo ensino/aprendizagem não apenas como um auxílio, mas também como um elemento configurador da relação professor, aluno, conteúdos e objetivos que se refletem nos processos cognitivos e atitudinais dos estudantes. Podem ser úteis em diversas situações, tais como na introdução de novos conteúdos, para despertar a motivação e curiosidade, para simular experiências de química que seriam perigosas em laboratório ou exigiriam tempo e recursos não disponíveis, para apresentar situações às quais os alunos não teriam facilidade de acesso, para demonstrar e ilustrar fenômenos e processos demorados como, por exemplo, o crescimento de uma planta, etc. Enfim, são várias as possibilidades de utilização do vídeo como recurso audiovisual (Moran, 1995). Contudo, nem sempre o recurso audiovisual é empregado de forma a contemplar as funções citadas anteriormente. Moran (1995) descreve algumas formas inadequadas de seu uso:

- Vídeo tapa-buraco: utilizado em virtude de um problema inesperado, como ausência do professor. Parece ser útil, mas não deve ser uma prática frequente, pois desvaloriza o uso do vídeo e o aluno pode associar o vídeo a não ter aula.

- Vídeo-enrolação: exibir um vídeo desvinculado da matéria. O aluno percebe que o vídeo é usado como forma de camuflar a aula. Pode concordar na hora, mas discorda do seu mau uso;

- Vídeo-deslumbramento: o professor passa vídeo em todas as aulas, esquecendo-se de outras possibilidades. $\mathrm{O}$ uso exagerado do vídeo diminui a sua eficácia e empobrece as aulas;

- Só vídeo: utilização do vídeo desacompanhada do assunto da aula e sem retorno a alguns momentos importantes.

Considerando a experimentação e o uso de recursos audiovisuais como importantes ferramentas no processo educacional e cultural, a proposta aqui apresentada é de que a experimentação mediante vídeo possa também se constituir em um recurso alternativo para que professores realizem aulas experimentais. Há, atualmente, uma verdadeira infinidade de experimentos disponíveis na internet. Ademais, tem-se a possibilidade do próprio professor, inclusive com seus alunos, produzir tais materiais, com um celular ou câmera. Dessa forma, este trabalho procura abrir uma discussão de quais possibilidades e limites para a experimentação encerrariam o vídeo, a partir da seguinte questão: como estudantes de licenciatura em química 
enxergam o uso de vídeos para a experimentação em relação a aspectos como: situações de uso, vantagens, limites, aprendizagem, motivação e funcionamento da ciência?

\section{Metodologia}

A pesquisa foi realizada com quarenta e um estudantes de licenciatura em química, sendo 18 da Universidade Federal de São Carlos (UFSCar) e 23 da Universidade Federal de Rondônia (UNIR). A escolha de duas universidades tão distintas quanto à localidade, público alvo e mesmo estrutura do curso visou analisar se o estudo de diferentes disciplinas relacionadas à química e seu ensino bem como as diferenças socioculturais influencia ou influenciou o pensamento de um tema específico - a experimentação com auxílio de tecnologias da comunicação. O principal critério de seleção dos participantes da pesquisa foi o fato de já terem estudado o uso de recursos didáticos, sobretudo a experimentação, no ensino de química. Por isso, os participantes deveriam ter cursado (ou estar em fase final de conclusão de) disciplinas como Metodologia de Ensino, Experimentação e Instrumentação para o Ensino. Como instrumento de coleta de dados foi utilizado um questionário (Quadro 1).

Quadro 1 - Questionário utilizado como instrumento de coleta de dados.

1. Você já vivenciou alguma situação, enquanto estudante, de uso de vídeos por seus professores de Química? Se sim, descreva.

2. Você acha possível o uso da experimentação em sala de aula por meio de vídeos? （） Sim （） Não. Justifique.

3. Em quais situações você acredita que o uso da experimentação mediante vídeos seria interessante? Justifique sua opinião para cada situação apresentada.

4. Você acredita que a experimentação mediante vídeos tenha vantagens em relação à experimentação em tempo real (realização do experimento pelo professor e/ou pelo aluno "ao vivo" no laboratório e/ou em sala de aula)? ( ) Sim ( ) Não. Se sim, quais seriam elas?

5. Você acredita que a experimentação mediante vídeos tenha limites em relação à experimentação em tempo real? ( ) Sim ( ) Não. Se sim, aponte quais seriam eles?

6. Em termos de aprendizagem, você acredita que ela possa acontecer da mesma forma seja com o uso de experimentos em tempo real ou com o uso de experimentos apresentados por vídeos? ( ) Sim ( ) Não. Justifique.

7. Em termos de motivação, você acredita que ela possa ocorrer da mesma forma seja com o uso de experimentos em tempo real ou com o uso de experimentos apresentados por vídeos? ( ) $\operatorname{Sim}($ ) Não. Justifique.

8. Em termos da aprendizagem sobre o funcionamento da Ciência (fundamentos sobre como a Ciência é construída, tarefas dos cientistas e da Ciência), você acredita que isso possa ocorrer da mesma forma seja com o uso de experimentos em tempo real ou com o uso de experimentos apresentados por vídeos? ( ) $\operatorname{Sim}$ ( ) Não. Justifique. 
Tal questionário foi elaborado no sentido de se avaliar as opiniões dos estudantes tanto de forma quantitativa como qualitativa acerca do uso de vídeos para a experimentação. Todas as questões admitiam como respostas 'sim' e 'não' e solicitavam justificativas.

Após aplicação e análise dos questionários, as respostas (sim, não) foram contadas. Com isso, obteve-se um quadro geral, em termos de quantidade, sobre como os graduandos em licenciatura em química pensam o uso de vídeos para a experimentação. Em relação às justificativas, após a leitura inicial de todas, foram identificadas unidades de significação nas respostas, sendo as mesmas dispostas em categorias, que representam o agrupamento de unidades de significação em comum. Após essa primeira categorização, procedeu-se nova leitura, no intuito de identificar novas unidades de significado e/ou reagrupamento das respostas em novas categorias ou sub-categorias (Moraes, 2003). Dessa forma, obteve-se um conjunto de respostas que representa as principais ideias dos estudantes em relação às variáveis investigadas. Os resultados foram apresentados de forma descritiva. As categorias identificadas a partir das unidades de significado encontram-se sublinhadas no texto para facilitar a identificação.

\section{Resultados e discussão}

Inicialmente, os dados foram analisados separadamente, de acordo com a instituição, almejando verificar possíveis diferenças de crenças e concepções devido às diferenças formativas. Todavia, devido à similaridade dos resultados, estes foram apresentados sem tal discriminação. Vale destacar ainda, que em algumas questões o somatório das categorias ultrapassa o número de respondentes devido ao aparecimento de mais de uma unidade de significação para o mesmo estudante. Já em outras situações, o número de justificativas é inferior ao total pelo fato de alguns terem deixado de responder.

Na primeira questão, que abordou a vivência dos licenciandos em atividades didáticas envolvendo recursos audiovisuais, 27 estudantes responderam que nunca vivenciaram aulas de química com uso de vídeos. Por sua vez, 14 estudantes responderam positivamente, que já vivenciaram aulas de química com o uso de vídeos. Destes que vivenciaram tais atividades, a maioria coloca que a utilização desse recurso pouco auxiliou a aprendizagem, em geral pelo uso desvinculado do conteúdo e pela falta de objetivos:

“já, muitas vezes vídeos completamente desvinculados da disciplina ou conteúdo abordado."

"sim o professor passou um filme... que não tinha nada haver com a disciplina..."

"sim já vivenciei situações em que o professor fez o uso de vídeos, porém o objetivo da aula não ficou devidamente claro e a linguagem do vídeo não possibilitou a construção do conhecimento."

"sim,... mas professor não explicou nada, foi embora e nunca mais falou nada sobre o vídeo."

R. B. E. C. T., vol 4, núm 2, mai./ago. $2011 \quad$ ISSN - 1982-873X 
O que se observa é que a maioria dos acadêmicos nunca vivenciou uma situação de ensino com o uso de vídeos ou filmes e, daqueles que vivenciaram alguma situação, nota-se certa frustração. Os acadêmicos recordam que o uso do recurso contribuiu muito pouco para a aprendizagem.

A ausência da utilização de recursos audiovisuais em aulas, não apenas de química, é realidade em muitas escolas. Tal problema pode estar associado ao fato de a escola não possuir tais recursos ou pela falta de interesse e de preparo (que pode envolver questões como falta de tempo e formação adequada) do professor em adotar esse tipo de atividade. Além disso, é possível perceber alguns usos inadequados segundo Moran (1995), como o vídeo tapa-buraco e o vídeo enrolação, que contribuem para a resistência futura desses estudantes no que tange ao uso de tal recurso.

Em relação à possibilidade do uso da experimentação em sala de aula por meio de vídeos, 29 estudantes responderam positivamente, achando possível seu o uso. Nas justificativas, nove estudantes argumentam que a experimentação por vídeos seria uma atividade interessante devido à visualização das imagens no vídeo ser mais significativa:

"... o aluno grava mais facilmente uma imagem do que uma aula oral."

"... os alunos através do vídeo vão observar os fenômenos que ocorrem no experimento."

“... casos onde é necessário se ter uma análise que pode passa despercebido quando feito apenas experimentalmente em sala..."

Cinco alunos descrevem que o experimento por meio de vídeos pode ser uma alternativa para experimentos que apresentam algum perigo ou risco aos alunos:

"inclusive nos casos de experimentos perigosos e de difícil execução."

"isso diminui o risco de acidentes ocorridos comumente em laboratório."

Também cinco alunos destacam que a experimentação por meio de vídeos depende da forma como a atividade é realizada, apontando para a importância de seu planejamento:

"deve-se fazer um planejamento da aula, onde seja possível a aplicação desse recurso"

"desde que seja um vídeo coerente com o que vem sendo estudado..."

Por sua vez, em três justificativas é assinalado que a experimentação por meio de vídeos é uma alternativa possível nos casos em que a escola não possua laboratório, ou na falta ou economia dos reagentes que seriam empregados na atividade: 
"é uma opção para solucionar a falta de laboratório e reagentes."

"não necessita de reagentes, vidrarias, portanto mais viável."

Em oposição aos 29 estudantes que veem possibilidades para a experimentação por meio de vídeos, 12 estudantes responderam contrariamente. Em todas as justificativas aparece a necessidade do contato direto com o experimento, alegando a vivência da prática como fator imprescindível:

"a experimentação deve ser tanto expositiva quanto participativa"

"o aluno precisa acompanhar o experimento ao vivo, para dar credibilidade"

"a prática deve ser vivenciada pelos alunos"

"acredito que o uso da experimentação deve ser feita em sala de aula,

professor/aluno, para que a aluno tenha o contato com vidrarias, reagentes,

etc..."

Para Arroio e Giordan (2006), a experimentação na química também pode ocorrer por simulação com vídeo, especialmente em situações em que a atividade no laboratório apresente perigo aos alunos, ou em experimentos que exigem muito tempo e/ou recursos inexistentes, como por exemplo, no caso da falta de determinados reagentes e equipamentos. Essas possibilidades para o desenvolvimento de atividades experimentais com o uso de vídeos também foram apresentadas pelos acadêmicos. Alguns também atribuem à periculosidade do experimento como o principal objetivo de se planejar um experimento com vídeo.

Outra possibilidade apontada foi a falta de estrutura da maioria das escolas. É realidade em muitas escolas brasileiras a falta de laboratórios, reagentes e certos equipamentos que seriam importantes à realização de experimentos. Há de se considerar, ainda, que diante da realidade brasileira, mesmo que o professor se empenhe na elaboração e uso de experimentos alternativos, o custo com materiais geralmente é de sua responsabilidade. Torna-se financeiramente complicado, nesse sentido, reproduzir vários experimentos em diferentes salas de aula, levando em conta o número de salas das quais o professor é responsável para obter um salário aquém do ideal. Este é outro aspecto no qual a experimentação por vídeos seria significativa, haja vista a redução de custo que pode promover.

Por outro lado, uma parcela menor dos acadêmicos considera que não seja possível aplicação de experimentos por vídeos. Como justificativa principal está a importância do aluno ter contato com o ambiente de laboratório, e o conhecimento que esse aluno deve ter na manipulação de vidrarias, reagentes e equipamentos, ou seja, habilidades técnicas de laboratório. Mas, a questão é: na experimentação com fins didáticos seria necessária a aquisição dessas habilidades? Hodson (1994) discute esse aspecto argumentando que tais habilidades são 
necessárias apenas para garantir a confiabilidade dos resultados experimentais, não tendo um fim em si e, portanto, não sendo essencial para a experimentação.

$\mathrm{Na}$ terceira questão, quando questionados em quais situações seria interessante o uso da experimentação mediante vídeos, em 10 respostas há destaque da experimentação mediante vídeos para a abordagem de alguns conceitos complexos e abstratos:

"modelo atômico, interações moleculares, acredito que visualizando esses conceitos tão abstratos melhoraria a compreensão."

"em todas as situações, principalmente nas mais abstratas, seria interessante $o$ uso de vídeos. Na parte de gases, $\mathrm{pH}$, pela mudança de cor de determinados materiais, ou seja, tudo que seja visível na experimentação e que faça o aluno associar conceitos concretos".

"em situações em que se faz necessário mostrar fenômenos submicroscópicos..."

"nos conteúdos mais complexos em que o professor teria mais dificuldades de ensinar..."

"depende do conteúdo... soluções, colóides, organização molecular e outros."

Aqui se observa uma valorização da observação como requisito fundamental nas atividades práticas. A elaboração conceitual em nível mental a partir dos resultados experimentais não tem tanto destaque, como se apenas os experimentos por si possibilitassem o acesso ao conhecimento.

Em nove respostas os estudantes apontam que o interessante da experimentação mediante vídeos seria em situações nas quais o experimento apresentasse risco na manipulação de certos reagentes e possibilidade de reduzir o tempo de realização:

\footnotetext{
"experimentos perigosos: a fim de evitar riscos aos alunos e ao ambiente escolar..."

"talvez em experimentos que levem muito tempo ou que possam oferecer perigo aos alunos".

"tempo reduzido: em vídeo, o experimento pode ser realizado de maneira eficaz, focando apenas nos objetivos da atividade."
}

Em 11 casos os estudantes novamente apresentam que a experimentação mediante vídeos seria importante quando não há laboratório ou faltam certos materiais e reagentes, ou ainda quando o experimento a ser realizado for complicado: 
"falta de estrutura: o experimento pode ser observado e discutido diversas vezes, sem a necessidade de laboratório e reagentes."

"quando o experimento for complexo..."

"em escolas sem recursos, pois facilita os experimentos em termos financeiros e práticos e em turmas que não tem bom comportamento..."

As situações colocadas pelos estudantes são bastante pertinentes e merecem reflexões. A elas podem ser acrescidas situações nas quais a quantidade de estudantes em sala é elevada, fato que torna a realização da aula experimental convencional muito difícil para o professor e também para os alunos. Visto que o elevado número de alunos em um laboratório pode aumentar o risco de acidentes, além de ocasionar dificuldades de realização e observação uma vez que geralmente não há pessoal para auxiliar, o vídeo torna-se uma possibilidade viável para suplantar tal problema.

Quanto às vantagens da experimentação com uso de vídeos em relação à experimentação em tempo real (quarta questão), 10 pessoas acenaram positivamente, acreditando que a experimentação por vídeos tenha vantagens. Dentre as vantagens destacadas estão a redução de tempo e de custos do experimento (10 incidências):

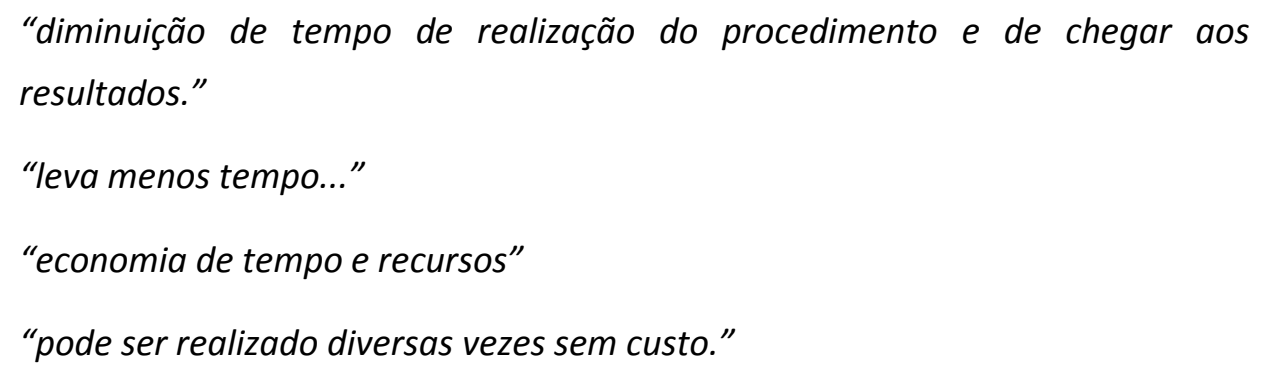

Ainda considerando as vantagens do experimento realizado por meio de vídeos, 3 discentes apontaram em suas justificativas a praticidade e objetividade da atividade, e 2 alunos citaram a isenção de erros experimentais como fator positivo.

Por outro lado, para 19 estudantes a experimentação em vídeo não apresentaria vantagem alguma em relação à experimentação realizada "ao vivo" pelo aluno ou professor, no laboratório ou em sala de aula. Provavelmente, estes alunos estão fortemente atrelados ao papel da função manipulativa da experimentação como motivadora por si. Doze estudantes não responderam a questão.

Estes resultados podem ser reflexos do fato de poucos estudantes terem participado de aulas com a utilização de recursos audiovisuais ou terem suas expectativas frustradas em tais situações, conforme demonstrado para a questão 1. Assim, esses acadêmicos acabam por negligenciar as possibilidades de realização da experimentação de formas não convencionais como é o caso da experimentação por vídeos. Galiazzi e Gonçalves (2004) ressaltam que a visão 
empirista sobre as atividades experimentais dos acadêmicos de cursos de Licenciatura em Ciências é oriunda da concepção de experimentação empirista dos professores do Ensino Médio e dos professores do Ensino Superior. O papel atribuído à observação como produtora de aprendizagem também pode ter a mesma gênese.

Em contraste com as opiniões negativas, a experimentação em vídeos pode apresentar várias vantagens em relação à experimentação em tempo real, conforme descrito por alguns acadêmicos. Dentre as vantagens apontadas estão a economia de tempo e de custos, visto que no experimento apresentado em vídeo o tempo pode ser reduzido e os custos com materiais e reagentes não existiriam, podendo esse experimento ser realizado quantas vezes fosse necessário para uma melhor captação dos detalhes do fenômeno.

Além das vantagens citadas pelos acadêmicos, a experimentação em vídeo pode ser utilizada de forma a explorar as propriedades que os recursos audiovisuais possuem. Por exemplo, nos experimentos em tempo real alguns fatos particulares podem não ser percebidos por um ou outro aluno, enquanto mediante os vídeos tais fatos podem ser visualizados diversas vezes, aumentado os detalhes com o uso de ferramentas como o zoom, o congelamento da imagem, assim como avançando ou retrocedendo os vídeos. Outras vantagens inerentes são aquelas associadas à falta de estrutura das escolas, como discutido anteriormente.

Quanto à quinta questão, sobre os limites da experimentação mediante vídeos em relação à experimentação em tempo real, apenas três acadêmicos responderam que a experimentação mediante vídeos não apresenta limitações. Dez estudantes não responderam e a maioria (28 estudantes) respondeu positivamente, acreditando que experimentação mediante vídeos apresenta limitações.

Em relação às justificativas, em treze delas é apontada como limitação a vivência do aluno com o ambiente de laboratório. É destacada ainda a necessidade do aprendizado de algumas noções de manipulação de equipamentos e materiais, obtidas a partir da interação ocorrida durante o experimento. Enfim, o contato direto do aluno com o experimento em tempo real contribuiria para a melhor aprendizagem:

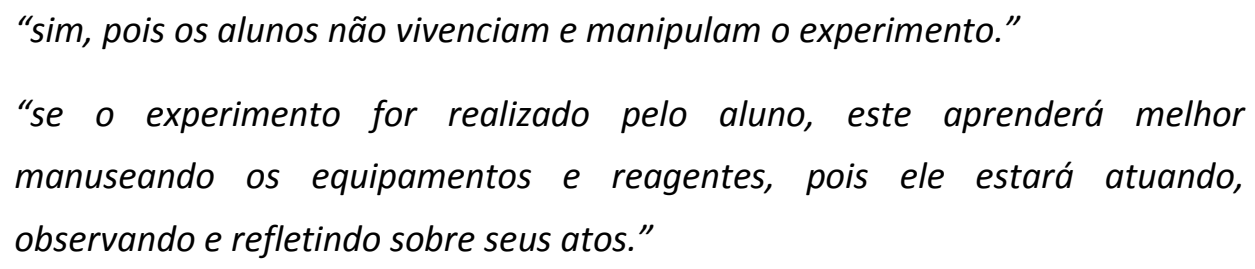

Quatro estudantes indicaram como limite o fato de certos experimentos apresentarem transformações que seriam perceptíveis apenas no experimento em tempo real, como, por exemplo, liberação de gás ou mudança de temperatura: 
"o aluno não pode sentir o cheiro característicos dos produtos, ou mesmo o calor liberado por uma reação exotérmica e outras sensações que só são vistas ao vivo."

"a parte sensitiva do laboratório, cheiros, calor."

Segundo 3 justificativas, a experimentação por vídeos apresenta limitações quanto ao tipo de vídeo a ser utilizado e a forma de apresentação deste:

"quanto a problematização do experimento. Há risco do ensino ser mecânico, se o professor não souber aplicar o instrumento de ensino."

"se o vídeo não apresentar passo-a-passo o experimento."

Para 2 estudantes os limites seriam a extinção de erros experimentais. Tais situações impediriam a contribuição da problematização dos erros experimentais, que também apresentam grande importância para o aprendizado:

"sempre apresenta os mesmos resultados, impedindo outras situações que também seriam aproveitáveis, afinal também aprendemos com isso."

Outro aluno aponta como limite a falta de recurso audiovisual nas escolas:

"escolas que não dispõe de equipamentos para a realização dessas aulas."

Dentre as limitações citadas a que apareceu com maior frequência foi a questão da vivência que o aluno deve ter no laboratório, ou seja, a interação ocorrida durante o experimento seria a responsável pelo aprendizado. Acredita-se, sem dúvida, que o contato do aluno com o ambiente de laboratório seja essencial. Por outro lado, o que se defende aqui é a realização da experimentação por vídeo como uma possibilidade para determinadas situações em que a experimentação em tempo real não possa ser realizada, ou ainda para explorar suas vantagens.

Todos os limites descritos são de grande relevância. É importante que a escolha do vídeo, por exemplo, contemple todos os detalhes do experimento, de forma que a sua apresentação sintetize os aspectos principais dos procedimentos e resultados, cabendo ao professor a escolha ou preparo desse vídeo de acordo com o objetivo e a finalidade que se pretende alcançar. Outro limite que parece evidente é o fato de que o experimento em vídeo seja isento de erros, caso que descartaria a possibilidade de uma discussão desse erro, o que seria de grande importância para a aprendizagem. Sobre isto Giordan (1999) descreve que uma experiência em que se admitem as possibilidades de erro e acertos pode promover uma reflexão racionalizada, que mantém o aluno comprometido com sua aprendizagem, onde ele próprio reconheceria o aprendizado como estratégia para a resolução de uma problemática. Todavia, a produção do vídeo pode incluir um erro experimental propositalmente, de modo que tais reflexões possam ser também suscitadas. 
Outra limitação importante que pode passar despercebida pelo professor seria quanto às peculiaridades de determinados experimentos. Alguns experimentos podem apresentar características peculiares como desprendimento de gases incolores ou ainda odores característicos de determinadas reações. Tais peculiaridades, que estão ligadas a sentidos outros que não a visão, não podem assim ser percebidas no vídeo. Essa seria uma limitação importante a ser considerada. Silva, Benite e Soares (2011) apontam a importância do odor nas atividades experimentais, sua relação com aspectos cognitivos e como esta poderia atuar favoravelmente na aprendizagem, dando mais significância aos experimentos.

Em termos de aprendizagem, para 16 acadêmicos a aprendizagem não acontece da mesma forma em experimentos com vídeos e experimentos em tempo real. Dentre as justificativas negativas, é novamente realçado o contato direto com o experimento (7 estudantes):

"porque o aluno não esta em contato com o experimento em si, o que facilita a compreensão do conteúdo."

"se o aluno faz a aprendizagem é mais produtiva."

Para estes estudantes a aprendizagem ocorreria de forma mais significativa no experimento em tempo real, pois o manuseio de equipamentos, vidrarias e reagentes, ou seja, as habilidades operacionais dentro do laboratório seria um fator essencial da aprendizagem.

Nove acadêmicos não responderam e outros 16 responderam positivamente, acreditando que a aprendizagem acontece da mesma forma em experimentos com vídeos e experimentos em tempo real. Nas justificativas também aparecem o papel do professor (5 justificativas) como agente da aprendizagem. Dependerá dele o planejamento prévio da atividade, bem como os objetivos, a escolha do experimento, a condução do experimento e as possíveis discussões e conclusões que o experimento requer:

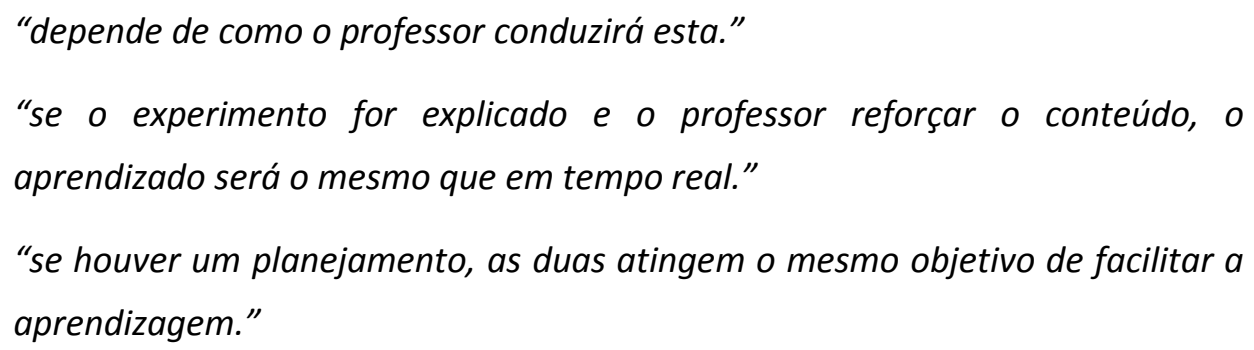

Em duas justificativas denota-se que a aprendizagem ocorreria da mesma forma, mas em certos casos ou atuando mutuamente:

"creio que a aprendizagem ocorrerá com o emprego dos dois métodos de forma coordenada, ambos são complementares para a aprendizagem." 
"não totalmente. Nem sempre. Em alguns casos, se torna mais eficiente o uso de vídeos e em outros casos, o uso da experimentação em tempo real..."

Outras justificativas (8 incidências) não foram agrupadas em uma categoria única por serem distintas ou não serem muito claras.

"sim, a aprendizagem pode acontecer das duas formas, mas em diferentes estágios de compreensão."

"se feitas as devidas anotações os alunos poderiam produzir relatórios com a mesma qualidade de um experimento ao vivo."

"o aluno esta motivado do mesmo jeito."

Comparando o total de respostas positivas com as respostas negativas, se percebe que os estudantes estão bem divididos, pois 16 acenam positivamente e 16 acenam negativamente sobre a possibilidade de aprendizagem. Para os acadêmicos que não acreditam na possibilidade da aprendizagem ocorrer igualmente em ambos os casos, a grande alegação é a necessidade do contato direto com experimento. Para Borges,

Métodos ativos de ensino-aprendizagem são entendidos como se defendessem a idéia de que os estudantes aprendem melhor por experiência direta. Embora verdadeiro em algumas situações, esse entendimento é uma simplificação grosseira. $O$ importante não é a manipulação de objetos e artefatos concretos, e sim o envolvimento comprometido com a busca de respostas/soluções bem articuladas para as questões colocadas, em atividades que podem ser puramente de pensamento em que o núcleo dessas atividades práticas não envolva necessariamente atividades típicas do laboratório escolar. (Borges, 2002, p. 295)

Ressalta-se que a aprendizagem é um processo que não depende apenas do recurso a ser empregado, mas sim das relações que se estabelecem durante a atividade (Gonçalves e Marques, 2006). Nesses termos, se considera que o simples desenvolvimento de atividades experimentais não facilita obrigatoriamente a aprendizagem conceitual.

Muitos acadêmicos acreditam que a aprendizagem é fruto do trabalho do professor, sendo este o único responsável pela aprendizagem. É claro que o professor tem grande responsabilidade no processo, cabendo a ele o planejamento da atividade e a preocupação com o conhecimento adquirido pelos alunos, estabelecendo conexões entre os conceitos já existentes e os novos a serem adquiridos. Todavia, este é um processo gradual que depende também do esforço do próprio aluno na reflexão, articulação e ampliação de suas ideias. Nesse sentido, entende-se que aluno e professor são igualmente sujeitos da aprendizagem e que esta acontece com a formulação e reformulação dos saberes. 
Para Freire (1998), as pessoas sabem de seus condicionamentos e de sua liberdade e encontram na vida pessoal e social barreiras que devem ser vencidas, chamadas de situaçõeslimites. Essas situações podem ser vistas como obstáculos que querem transpor ou ainda algo que deve ser rompido. Diante dessa perspectiva, a situação-limite pode ser entendida como um desafio, onde os alunos desafiados entendem que precisam agir e sentem a necessidade de aprender e superar o desafio ali posto. Uma proposta experimental que leve em conta tais fatores não se limitaria apenas à observação ou ao questionamento de conhecimentos prévios, mas sim todo um contexto educativo com base na construção de argumentos, no diálogo, na leitura e na escrita (Gonçalves e Galiazzi, 2004; Francisco Junior, Ferreira e Hartwig, 2008).

Diante da perspectiva de que a aprendizagem é um processo complexo, algo em permanente construção e que pode ser mediada pela experimentação, acredita-se na possibilidade de que a atividade experimental por meio de vídeos também possa atuar na construção de um novo conhecimento. Tal pensamento é calcado na consideração de que o experimento não promove a aprendizagem ou a motivação de forma intrínseca. Mesmo que o estudante não faça o experimento, existe a possibilidade de se registrar os dados, discutir com os colegas, levantar hipóteses, avaliar hipóteses e explicações, discutir as etapas do experimento. Enfim, a atividade experimental em vídeo também pode suscitar nos estudantes um pensamento reflexivo e crítico, os fazendo sujeitos da própria aprendizagem. Isso depende, em princípio, das atividades que acompanham o experimento e de como os aprendizes serão nelas envolvidos.

Em termos da motivação, se ela ocorreria da mesma forma em experimentos com vídeos e experimentos em tempo real, 9 estudantes não responderam e 11 acenaram positivamente. Nas justificativas aparecem aspectos como o tipo de experimento e a forma como é conduzido ( 5 estudantes):

"sempre buscando a maneira mais adequada de utilizar."

"se o experimento for interessante, a motivação vai ser igual nos dois casos."

No caso de 2 estudantes, o agente motivador da atividade experimental é o professor:

"isto pode acontecer, porem existe um peça importante nesse processo de motivação, a peça fundamental é humana, chama-se professor."

Em contrapartida, 21 estudantes responderam negativamente. Para estes a motivação não ocorre da mesma forma em experimentos com vídeos e experimento em tempo real. A maior parte das justificativas (13) se refere novamente à necessidade do aluno manipular o experimento. A monotonia e o fato dos vídeos se tornarem mecânicos também são destaques ( 7 estudantes): 
"o vídeo seria muito mecânico, creio que um deve ser complementar do outro."

"a motivação é melhor abrangida em tempo real porque em vídeos, tem pessoas que até dormem."

Um dos estudantes argumentou que "os experimentos apresentados por vídeos não trazem confiança".

Percebe-se que a maioria dos acadêmicos acredita que a motivação não aconteça da mesma. Para estes, a motivação é decorrente do contato direto do aluno com o experimento. No entanto, uma parcela dos acadêmicos acredita que a motivação aconteça da mesma maneira, visto que o próprio recurso audiovisual é um agente motivador e que a atividade experimental também desempenha esse papel. Mesmo assim, a motivação para alguns depende de como o professor conduzirá a atividade. Dessa forma, entende-se que as relações entre motivação e o processo de ensino e aprendizagem decorrem de certa complexidade (Gonçalves e Marques, 2006).

Aprendizagem e motivação estão interligadas. A motivação ou interesse é o resultado de uma carência do conhecimento (Soares, 2008), que gera assim uma necessidade de aprendizado. Quando há o interesse a aprendizagem ocorre naturalmente. Também a respeito, Laburú (2006 p. 388) destaca que a "motivação é indissociável do processo de desenvolvimento e promotora da expansão das capacidades próprias, assim a aprendizagem de qualidade é resultado da sinergia entre motivação e cognição".

A motivação pode ser dividida em duas categorias: a motivação extrínseca e a intrínseca. A motivação extrínseca pode ser entendida como um motivo externo que está associado a recompensas materiais e sociais ou de reconhecimento. Num contexto escolar a motivação extrínseca, por exemplo, está associada à avaliação de uma atividade, onde o aluno acredita que ao fazer uma tarefa será recompensado com notas, elogios ou prêmios. Diante disso, muitos acreditam que a motivação extrínseca é a única a ser considerada.

A motivação intrínseca está associada à escolha e realização de uma atividade, por sua própria causa, por ser interessante ou atraente. Existe no indivíduo um comprometimento espontâneo associado a uma orientação pessoal em situações desafiadoras referente ao prazer do próprio sucesso onde, por exemplo, a própria matéria de estudo desperta e impulsiona o aluno a se aprofundar e vencer os obstáculos que se apresentam no processo de aprendizagem (Laburú, 2004).

Gonçalves e Marques (2006) ressaltam a necessidade de se repensar a intenção de motivar para aprender, pois talvez seja interessante compreender que o sujeito precisa aprender para se sentir e manter-se motivado. Entende-se assim, que a problematização sobre o assunto estudado, o modo de trabalho em sala de aula, a autonomia e a avaliação, são exemplos de aspectos que 
não são exclusivos e nem obrigatoriamente inerentes às atividades experimentais, porém podem estar relacionados com a motivação dos estudantes.

Logo, a motivação pode ser reforçada por medidas educacionais baseadas em estratégias de ensino ou atividades que o professor pode escolher com total liberdade. Como dito anteriormente, atividades desafiadoras, ou situações-limites na concepção freiriana, podem ser referências para despertar o interesse do aluno. $O$ desafio pode ser colocado, por exemplo, em problemas do cotidiano que envolva o conteúdo de química e que seja aberto ao interesse do aluno. Dessa forma, acredita-se que na experimentação mediante vídeos ou na experimentação com manipulação exista a possibilidade de que a motivação ocorra da mesma forma. Tal hipótese está imbuída na tese de que a experimentação não promove uma motivação intrínseca. Assumindo que a motivação durante a experimentação é extrínseca, é de sobremaneira importante mostrar ao estudante as contribuições daquilo em sua vida.

Ainda é importante ressaltar que a motivação, assim como a aprendizagem, não é mérito exclusivo apenas de atividades experimentais, mas que deve ser desenvolvida em qualquer atividade cotidiana em sala de aula, bem como em atividades com vídeos.

Na última questão, sobre o funcionamento da ciência (como a ciência é construída, a tarefa dos cientistas e da ciência) e se essa discussão poderia acontecer da mesma forma em experimentos com vídeos e experimentos em tempo real, um total de 17 estudantes não respondeu. Por sua vez, 13 estudantes responderam positivamente. Estes acreditam que a aprendizagem sobre o funcionamento da ciência ocorreria da mesma forma. No que cinge às justificativas, estas são muito diferentes uma das outras, o que impossibilitou agrupá-las em categorias. Um estudante, por exemplo, argumenta que depende do professor introduzir tais conceitos e o senso crítico em relação ao papel da ciência:

"pois basta o professor conduzir o mesmo deixando bem claro estes pontos."

Outros argumentos caminham no seguinte sentido:

"acredito que para desenvolver um senso critico você deve conhecer os dois lados."

"as vezes, determinados vídeos ilustram melhor e contextualizam a experimentação na história, o que pode ser mais claro para o aluno."

"podemos explicar o funcionamento da Ciência usando os dois métodos, já que a ciência e a atividade dos cientistas podem ser discutidas."

"só vai mudar o meio de apresentação, mas o ponto crítico será questionado da mesma forma." 
Entretanto, 11 estudantes responderam negativamente. A principal justificativa é de que no experimento real o papel da ciência seria mais fortemente estabelecido, devido ao contato do aluno com o experimento ( 6 estudantes):

"o uso de experimento usados em tempo real ajudam muito mais os alunos do que experimentos realizados em vídeos"

"realizar um experimento ao vivo deixa a pessoa motivada a novas descobertas e faz com que a mesma se sinta um cientista, sensações que talvez o ensino por vídeo não transmita."

Diante dos resultados, percebeu-se que muitos acadêmicos não têm uma ideia ou concepção formada sobre o papel e o funcionamento da ciência e da importância deste conhecimento para o ensino de química. Esses resultados podem estar concatenados à concepção de ciência dos estudantes o que, por seu turno, pode estar associado à ausência de discussões dessa natureza nos cursos de química. Sendo assim, a visão de ciência apresentada pela maioria dos acadêmicos em formação pode ser considerada afastada do que a literatura contemporânea considera fundamental a propósito da produção científica e do que significa hoje a ideia de ciência (Praia, Cachapuz e Gil-Pérez, 2002).

A visão de ciência empírica e indutiva assume o conhecimento científico como verdade provada ou descoberta originada de observações de um determinado fenômeno, por uma mente livre de pré-concepções e sentimentos, para se chegar a generalizações cientificamente válidas. Para muitos professores e estudantes as atividades experimentais com fins didáticos têm a mesma finalidade do que a atividade experimental feita com fins científicos. Assim, acabam por reproduzir o método científico com valorização excessiva da observação, considerando esse método e a ciência como algo infalível (Borges, 2002). Conforme aponta o mesmo autor:

Os Parâmetros Curriculares Nacionais para o Ensino Médio propõem que o ensino de ciências deve propiciar ao educando compreender as ciências como construções humanas, entendendo como elas se desenvolvem por acumulação, continuidade ou ruptura de paradigmas, relacionando o desenvolvimento científico com a transformação da sociedade. (Borges, 2002, p. 294)

Entende-se que qualquer que seja a atividade proposta, a experimentação por vídeo ou a experimentação em tempo real, seria viável discutir concepções mais contemporâneas de ciência, em ruptura com a visão empirista/indutivista. É fundamental que os alunos tomem consciência da construção dinâmica do conhecimento, das suas limitações, da constante luta em busca não de certezas, mas de um melhor e mais útil conhecimento (Praia, Cachapuz e Gil-Pérez, 2002). 


\section{Considerações finais}

Apesar da diferente realidade social e cultural, a concepção sobre o uso da experimentação por meio de vídeos praticamente não se difere entre os participantes da pesquisa. É notório que tal possibilidade não foi discutida nos cursos em cuja pesquisa foi conduzida. Apesar de todos terem cursado ou estar concluindo disciplinas que tratam do tema experimentação, alguns estudantes apresentam posições distintas no momento de avaliar o uso de vídeos para tal finalidade.

Quanto às possibilidades do uso da experimentação mediante vídeos, a contribuição dos estudantes foi significativa, apesar de muitos se esquivarem diante da possibilidade de realização dessa atividade, receosos principalmente quanto à preparação do professor no planejamento e na realização dessa atividade. Ainda assim, admitem que para o ensino de química, o uso recursos audiovisuais é de grande valia. As situações levantadas como possíveis para a experimentação por meio de vídeos foram sustentadas por fatores como periculosidade dos experimentos realizados em tempo real, custos com materiais e reagentes, ausência de laboratório nas escolas e a redução de tempo da atividade. Em contrapartida, os fatores para a não realização de tal atividade referem-se excessivamente à importância da participação do aluno na manipulação da atividade experimental.

Quanto à aprendizagem, há certa dissonância. Os participantes encontram-se divididos entre a necessidade da manipulação e da observação e entre o papel do professor. Em nenhum dos casos, no entanto, o papel e o comprometimento do próprio aluno são tocados. No caso da motivação, a maior parte ( 21 de 41 estudantes) se posicionou contrariamente no que concerne à possibilidade dos vídeos de experimentos motivarem tanto quanto os experimentos. Os argumentos foram pautados (novamente) na importância da manipulação e na monotonia que alguns vídeos podem originar. Tais estudantes parecem atribuir à experimentação uma espécie de motivação intrínseca decorrente do contato com o experimento, como se tal contato fosse suficiente para a motivação e, por vezes, desconsiderando o fato dos recursos audiovisuais também abarcar tal função.

A concepção de ciência apresentada pela maioria dos acadêmicos de ambas as universidades parecem estar pautadas na concepção empirista/indutivista. Isso pode ser revelado tanto pelas dificuldades em responder a essa questão como pelas próprias respostas. A visão de ciência linear apresentada pelos acadêmicos pode decorrer da formação histórica à qual estão submetidos no que se refere à compreensão do que e como se faz na ciência.

Por último, ressalta-se aqui que a proposta é de que a experimentação em vídeo possa ser útil em situações em que não seja possível a experimentação em tempo real, além de momentos 
em que seja mais interessante explorar as suas vantagens, como em experimentos demorados, quando se enseja focar detalhes que podem ser repassados ou mais bem visualizados com o aumento do zoom, ou ainda para diminuir custos. Assim como a experimentação em tempo real, a atividade em vídeo também apresenta vantagens e limitações e, portanto, estas podem ser práticas conjugadas e complementares. Ainda há de se considerar que atividade experimental, seja ela em vídeo ou em tempo real, deve ser encarada não apenas como um mero recurso pedagógico, mas sim uma atividade que possibilita ao aluno um desenvolvimento de habilidades, como o diálogo, a argumentação, a análise de informações, a escrita, a leitura, dentre outras. Estas, conjuminadas com a problematização do conteúdo a ser abordado são de extrema importância para o desenvolvimento pessoal e social, bem como para a organização e a construção de um conhecimento científico mais crítico.

\section{Agradecimentos}

Os autores agradem aos licenciandos e licenciandas da UNIR e da UFSCar que gentilmente se disponibilizaram a participar da pesquisa. Ao prof. Dr. Luiz Henrique Ferreira da Universidade Federal de São Carlos (UFSCar) pela colaboração na coleta dos dados. Ao Conselho Nacional de Desenvolvimento Científico e Tecnológico - CNPq (Processo 575471/2008-5 do Edital MCT/CNPq/CT-Amazônia 055/2008). À Coordenação de Aperfeiçoamento de Pessoal de Nível Superior - CAPES pela bolsa de Iniciação à Docência (R. I. dos Santos) e de Coordenação de Área (W. E. Francisco Junior).

\section{Referências}

Arroio, A.; Giordan, M. O vídeo educativo: aspectos da organização do ensino.

Química Nova na Escola, n.24, p. 8-11, 2006.

Borges, A. T. Novos rumos para o laboratório escolar de ciências. Caderno Brasileiro de Ensino de Física, v. 19, n. 3, p. 291-313, 2002.

Corrêa, R. G.; Ferreira, L. H. O uso do filme didático Cavernas: sob o olhar da química com alunos de ensino médio. XIV Encontro Nacional de Ensino de Química, Curitiba, 2008. Anais ...Disponível em:

<http://www.quimica.ufpr.br/eduquim/eneq2008/lista_area_MD.htm> Acesso em 20 de julho de 2010.

Francisco Junior, W. E.; Ferreira, L. H.; Hartwig, D. R. Experimentação problematizadora: fundamentos teóricos e práticos para a aplicação em salas de aulas

R. B. E. C. T., vol 4, núm 2, mai./ago. $2011 \quad$ ISSN - 1982-873X 
de Ciências. Química Nova na Escola, n. 30, p. 34-41, 2008.

Freire, P. Pedagogia da Esperança - um reencontro com a pedagogia do oprimido. $5^{\circ}$ ed. São Paulo: Paz e Terra, 1998.

Galiazzi, M. C.; Rocha, J. M. B.; Schmitz, L. C.; Giesta, S. M.; Gonçalves, F. P. Objetivos das atividades experimentais no ensino médio: a pesquisa coletiva como modo de formação de professores de Ciências. Ciência \& Educação, v. 7, n. 2, p. 249-263, 2001.

Galiazzi, M. C.; Gonçalves, F. P. A natureza pedagógica da experimentação: uma pesquisa na licenciatura em química. Química Nova, v. 27, n. 2, p. 326-331, 2004.

Giordan, M. O papel da experimentação no ensino de Ciências. Química nova na Escola, n. 10, p. 43-49, 1999.

Gonçalves, F. P.; Galiazzi, M. C. A natureza das atividades experimentais no ensino de ciências: um programa de pesquisa educativa nos cursos de Licenciatura. In: MORAES, R.; MANCUSO, R. (Org.). Educação em Ciências: produção de currículo e formação de professores. ljuí: Ed. Unijuí, 2004, p. 237-252.

Gonçalves, F. P.; Marques, C. A. Contribuições pedagógicas e epistemológicas em textos de experimentação no ensino de química. Investigações em Ensino de Ciências, v. 11, n. 2, p. 219$238,2006$.

Hodson, D. Hacia un enfoque más crítico del trabajo de laboratorio. Enseñanza de las Ciencias, v.12, n.3, p. 299-313, 1994.

Laburú, C. E. Fundamentos para um experimento cativante. Caderno Brasileiro de Ensino de Física, v. 23, n. 3, p. 383-405, 2006.

Marcelino Júnior, C. A. C.; Barbosa, R. M. N.; Campos, A. F.; Leão, M. B. C.; Cunha, H. S.; Pavão, A. C. Perfumes e Essências: a utilização de um vídeo na abordagem das funções orgânicas. Química Nova na Escola, n. 19, p. 15-18, 2004.

Moraes, R. Uma tempestade de luz: a compreensão possibilitada pela análise textual discursiva. Ciência \& Educação, v. 9, n. 2, p. 191-211, 2003.

Moran, J. M. O vídeo na sala de aula. Comunicação e Educação, v.2, p. 27-35, 1996.

Oliveira, C. M. A.; Carvalho, A. M. P. Escrevendo em aulas de ciências. Ciência \& Educação, v. 11, n. 3, p. 347-366, 2005.

Praia, F.; Cachapuz, A. F. C.; Gil-Pérez, D. Problema, teoria e observação em 
ciência: para uma reorientação epistemológica da educação em ciência. Ciência \& Educação, v.8, n. 1, p.127-145, 2002.

Silva, V. A.; Benite, A. M. C.; Soares, M. H. F. B. Algo Aqui Não Cheira Bem...A Química do Mau Cheiro. Química Nova na Escola, v. 33, n. 1, p. 3-9, 2011.

Soares, M. H. F. B. Jogos para o Ensino de Química: Teoria, Método e Aplicações. Guarapari-ES: Ex Libris, 2008.

Wilmo Ernesto Francisco Junior. Departamento de Química, Universidade Federal de Rondônia UNIR, Porto Velho-RO. Doutor em Química (tese em Educação Química). Coordenador Institucional do PIBID (Programa Institucional de Bolsa de Iniciação à Docência) da UNIR. wilmojr@bol.com.br

Railane Inácio dos Santos. EEEFM Castelo Branco. Professora da rede estadual de educação em Rondônia. Licenciada em Química pela UNIR e ex-bolsista do PIBID-UNIR área de Química. railaneunir@yahoo.com.br 